\title{
Effect of herbicide resistance endowing three ACCase mutations on seed germination and viability in American slough grass (Beckmannia syzigachne Steud. Fernald)
}

Long Du², Shuang Bai ${ }^{1}, \mathrm{Qi} \mathrm{Li}^{1}$, Mingjing $\mathbf{Q u}^{2}$, Guohui Yuan ${ }^{1}$, Wenlei Guo ${ }^{1}$, and Jinxin Wang ${ }^{1^{*}}$

\section{ABSTRACT}

American slough grass (Beckmannia syzigachne Steud. Fernald) is an annual grass which has developed resistance to acetyl-coenzyme A carboxylase (ACCase) inhibitors, and the major mechanism of resistance is target site based. Target site resistance-conferring mutations may confer pleiotropic effects on a weed's life cycle. The effects of three American slough grass spontaneous ACCase mutations (Ile1781Leu, Trp2027Cys and Ile2041Asn) on seed germination and viability under different experimental factors had been investigated in this paper. Seeds containing homozygous 1781Leu/Leu ACCase showed a greater germination under salt and osmotic stress, but no fitness variation in optimal experimental conditions. Homozygous 2027Cys/Cys ACCase caused nonsignificant effects on seed germination in optimal experimental conditions, but caused a greater germination after $16 \mathrm{~d}$ incubation at $40{ }^{\circ} \mathrm{C}$ and $100 \% \mathrm{RH}$. Homozygous 2041Asn/Asn ACCase tended to cause nonsignificant effects on seed germination or seed viability. Finally, an obvious population effects on seed germination was observed between six subpopulations, which indicated that fitness assessing should be measured in resistant and susceptible individuals that share a similar genetic background. These findings suggest that the absence of fitness penalty associated with these three homozygous mutant ACCase alleles may be a contributing factor for resistance spread.

Key words: ACCase gene mutation, Beckmannia syzigachne, fitness cost, homozygote.

${ }^{1}$ Shandong Agricultural University, College of Plant Protection, Shandong Tai'an 271018, China.

"Corresponding author (wangjx@sdau.edu.cn).

${ }^{2}$ Shandong Peanut Research Institute, Shandong Qingdao 266100, China.

Received: 3 January 2017

Accepted: 3 May 2017.

doi:10.4067/S0718-58392017000200142

\section{INTRODUCTION}

Acetyl-coenzyme A carboxylase (ACCase) (EC6.4.1.2) is a biotinylated enzyme that catalyzes the first step of fatty acid biosynthesis (Harwood, 1988; Devine, 1997). ACCase is the target of widely used commercial ACCase-inhibiting herbicides (hereafter referred to as ACCase herbicides) which includes three different classes: aryloxyphenoxypropionates (APPs), cyclohexanediones (CHDs) and the more recent phenylpyrazoline class herbicide pinoxaden (DEN). The intensive and persistent use of ACCase herbicides exerted an extremely drastic selective pressure on weeds, and selected 47 ACCase-resistant species (Heap, 2016). In most reported cases, the major mechanism of evolved resistance is ACCase gene mutation leading to amino acid substitutions. To date, 13 distinct resistance-endowing amino acid substitutions located at seven conserved amino acid residues in CT domain of the ACCase gene have been reported (Du et al., 2016). It is often alleged that genes conferring adaption to a new environment often have negative pleiotropic effects on fitness in the absence of the selective pressure in the whole plant life cycle (Purrington, 2000; Strauss et al., 2002; Vila-Aiub et al., 2009), and this has been strongly confirmed in artificial mutants of Arabidopsis thaliana with a homogenized genetic background (Roux et al., 2004). This negative pleiotropic effects may reveal the strategy of herbicide resistance. So, it is very important to illustrate the fitness alterations which may be manipulated in making resistance-management strategies (Jasieniuk et al., 1996).

Making an accurate genetic background control plays an important role in illustrating resistance cost between resistant and susceptive genotypes or phenotypes (Bergelson and Purrington, 1996; Vila-Aiub et al., 2009; Yu et al., 2010; Vila-Aiub et al., 2011; Li et al., 2013b), and this requires that herbicide-resistant individuals should be compared with susceptible individuals with a similar genetic background (Bergelson and Purrington, 1996). Fitness cost associated with mutant acetolactate synthase (ALS) conferring resistance to chlorsulfuron was observed in transformed A. thaliana under good control of background (Bergelson et al., 1996; Purrington and Bergelson, 1997). A significant fitness cost associated with Asp2078Gly ACCase was identified in Alopecurus myosuroides and Lolium rigidum under homogenized genetic background (Menchari et al., 2008; Vila-Aiub et al., 2015). All above-mentioned studies are targetsite resistance (TSR) and possessed one resistance mechanism. As for non-target-site resistance (NTSR) or resistance with unknown mechanism, the test must be designed under a relative 
homogenized background (Vila-Aiub et al., 2005a; 2005b; Pedersen et al., 2007; Vila-Aiub et al., 2009).

American slough grass (Beckmannia syzigachne Steud. Fernald) is a severely harmful poaceae weed of wheat (Triticum aestivum L.) and oilseed rape (Brassica napus L.) rotated with rice (Oryza sativa L.) field and is widely distributed around China especially in the Yangtze River delta and southwest region of China. The wide spread use of fenoxaprop-p-ethyl (belonging to acetylcoenzyme A carboxylase inhibitor family) has resulted in the general failure to control this weed (Li et al., 2013a; 2014; Tang et al., 2015). In this test, we used segregating American slough grass subpopulations to make a similar genetic background of resistant and sensitive individuals. Six American slough grass subpopulations were produced with all seeds individually homozygous for Leu1781Ile, Cys2027Trp and Asn2041Ile ACCase mutations which arose independently. Pleiotropic effects of those mutation alleles on seed germination and viability were examined.

\section{MATERIALS AND METHODS}

\section{Plant material}

Three field-evolved ACCase herbicide-resistant American slough grass populations, previously analyzed by ACCase molecular analysis, collected in 2011 and 2012 were used to produce six subpopulations. In order to make the genetic background of wild-type (W/W) and homozygous mutant seeds $(\mathrm{M} / \mathrm{M})$ similar as much as possible, we used batches of American slough grass seeds that shared a genetic background but were wild-type (W/W) and homozygous mutant $(\mathrm{M} / \mathrm{M})$ at the ACCase locus. The seed batches were the same as those used to establish the cross-resistance patterns associated with Ile1781Leu, Trp2027Cys and Ile2041Asn ACCase gene mutations in American slough grass (Du et al., 2016).

Field samples were collected at three different locations in China and then were analyzed by ACCase genotyping and sequencing (Du et al., 2016). Only one mother plant heterozygous (W/M) for one specific mutant ACCase allele and contained no other known mutant ACCase alleles was used to produce subpopulation within one field sample. Each mother plant was cultivated appropriately and isolated within a pollen-proof enclosure at the time of pollination. Seeds from per plant were collected as a bulk sample and stored at room temperature for 2-mo to enable after-ripening, then germinated and grown to the 3-leaf stage, and then genotyped as above described. Ten wildtype (W/W) and 10 homozygous mutant (M/M) ACCase plants from the same bulk sample were selected as mother plants to produce seeds used for subsequent experiments. Each group of 10 plants was cultured as above described. Ripe seeds were harvested from each group of 10 plants and labelled as described in Table 1. Ripe seeds were shook down and bulked on 22 May and 13 June in 2014, respectively. The seeds harvested on 13 June were used in the following repeated experiments.
Table 1. American slough grass populations used to produce the segregating subpopulations.

\begin{tabular}{lcccl}
\hline Populations & Year & Location & $\begin{array}{c}\text { Mutational } \\
\text { pattern }\end{array}$ & \multicolumn{1}{c}{$\begin{array}{c}\text { Derived } \\
\text { subpopulations }\end{array}$} \\
\hline JS-04 & 2011 & Jiangsu Danyang & Ile1781Leu & $\begin{array}{l}\text { I/I1781-JS-04 } \\
\text { L/L1781-JS-04 }\end{array}$ \\
AH-12 & 2012 & Anhui Lujiang & Trp2027Cys & $\begin{array}{l}\text { W/W2027-AH-12 } \\
\text { C/C2027-AH-12 }\end{array}$ \\
JS-32 & 2012 & Jiangsu Jintan & Ile2041Asn & $\begin{array}{l}\text { I/I2041-JS-32 } \\
\text { N/N2041-JS-32 }\end{array}$ \\
& & & &
\end{tabular}

aperived wild-type segregating subpopulation.

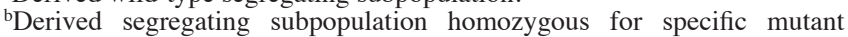
ACCase.

\section{Seed germination}

Two types of seeds were used in germination test: seeds collected freshly and seeds stored for 4-mo. Fresh seed germination test was conducted on the day they were collected. In order to simulate the natural germination time regime of American slough grass, seeds were stored with silica-gel desiccant for 4-mo at room temperature, and then used in stored seed germination test (Délye et al., 2013).

Seed germination test was conducted by depositing 15 seeds in 9-cm Petri dishes containing two layers of filter paper soaked with $5 \mathrm{~mL}$ distilled water. In order to detect effects of specific ACCase mutation on seed germination, optimal experimental conditions for American slough grass germination were used: a constant temperature of $10{ }^{\circ} \mathrm{C}$ with a 12-h light cycle (11000 Lux) in growth chamber (Rao et al., 2008). Petri dishes were sealed with Parafilm (American National Can, Greenwich, Connecticut, USA) to avoid water losses, and water was added as necessary. Seeds with visible radicles were considered to be germinated, and germinated seeds were removed and their removal date registered. Ten germinated seeds of each group were sown in individual plastic pots and then used for genotyping.

\section{Effect of $\mathrm{pH}$}

Seeds of derived wild-type and homozygous mutation genotypes were moistened using buffer solutions with $\mathrm{pH}$ values $4,6,8$ and 10 prepared according to Chachalis and Reddy (2000). Distilled water ( $\mathrm{pH} 7.6)$ was used as the control. All the Petri dishes were incubated under optimal experimental conditions mentioned above. The number of germinated seeds was recorded $18 \mathrm{~d}$ after the start of germination test.

\section{Effect of osmotic stress and $\mathrm{NaCl}$ salinity stress}

Polyethylene glycol 6000 (PEG-6000) is chemically an inert and non-toxic chemical substance with high molecular weight. Different PEG-6000 concentrations were prepared to control $0,-0.1,-0.2,-0.3,-0.4,-0.5$, and -0.6 MPa osmotic potential (Rao et al., 2008). Seeds grown in solution cultures were subjected to $0,10,20,40,80,160$, and $320 \mathrm{mM}$ solutions of $\mathrm{NaCl}$. Germination tests were carried out in growth chamber as mentioned above. 


\section{Accelerated ageing experiment}

The accelerated ageing test is one of the most frequently used tests to evaluate the physiological potential of seeds. For the accelerated ageing test procedure, seeds of derived six subpopulations were placed uniformly in $9 \mathrm{~cm}$ Petri dishes containing one layer of filter paper, being kept at $100 \% \mathrm{RH}$ and $40{ }^{\circ} \mathrm{C}$ for $0,2,4,8,12$ and $16 \mathrm{~d}$ (Hampton and Tekrony, 1995). After each period of exposure to the accelerated ageing test, germination was determined.

\section{Statistical analyses}

All data were expressed as percentages. All experiments were treated as a randomized complete block design with four replicates and all experiments were repeated. ANOVA was performed in SPSS software (Version 20.0; IBM Corp., Armonk, New York, USA) on nontransformed percent germination data because arcsine square transformation did not significantly improve homogeneity of variance. Significant differences among treatment means were identified by Tukey's HSD test $(\alpha=0.05)$. Otherwise regression analysis was used where appropriate.

\section{RESULTS}

\section{Genotypes and phenotypes of seeds at the ACCase locus}

Ten germinated seeds of each subpopulation selected in germination tests were used for genotyping. Result confirmed that all seeds homozygous for specific mutant ACCase (1781Leu/Leu, 2027Cys/Cys and 2041Asn/Asn hereafter referred to as $1781 \mathrm{M} / \mathrm{M}, 2027 \mathrm{M} / \mathrm{M}$ and $2041 \mathrm{M} / \mathrm{M}$, respectively) or wild-type ACCase (1781Ile/Ile, 2027Trp/ Trp and 2041 Ile/Ile hereafter referred to as $1781 \mathrm{~W} / \mathrm{W}$, $2027 \mathrm{~W} / \mathrm{W}$ and $2041 \mathrm{~W} / \mathrm{W}$, respectively), respectively. Herbicide dose-response experiments confirmed significant differences in the resistance patterns of homozygous mutant ACCase plants and wild-type plants within the same original field population (Du et al., 2016). All three subpopulations segregating for specific ACCase mutation conferred resistance to fenoxaprop-p-ethyl, while all three subpopulations of derived wild-type genotypes were susceptible to fenoxaprop-p-ethyl (Du et al., 2016). Each two subpopulations (e.g. I/I1781-JS-04 and L/L1781-JS-04) derived from the same original field population shared a common genetic background, except for mutant alleles conferring herbicide resistance.

\section{Seed germination}

A three-parameter sigmoidal model $y(\%)=a /(1+\exp (-(x$ $\left.-t_{G 50}\right)(b)$ ) was fitted to the germination values (\%) of fresh seeds and stored seeds (SigmaPlot V12.0, Systat Software, San Jose, California, USA). Where $y$ is cumulative germination over time $x, a$ is the maximum germination (\%), $t_{G 50}$ is the time to reach $50 \%$ of final germination (d) and $b$ indicates the slope around $t_{G 50}$. Parameter $b$ provides an indication of the distribution of the response (germination) over time (Vila-Aiub et al., 2005b). The degree of seed dormancy was reduced after stored. A significant reduction in seed germination time was observed in stored seeds (Figure 1, Table 2). The seed germination plateau was reached in 17-26 d for fresh seeds, and in 10$12 \mathrm{~d}$ for stored seeds. Sigmoidal regressions identified a significant population effect on the germination function. Time to reach $50 \%$ germination $\left(\mathrm{T}_{\mathrm{G} 50}\right)$ values for fresh seeds derived from population JS-04 were 16.3 and $15.7 \mathrm{~d}$, obviously faster than fresh seeds derived from populations AH-12 (25.1 and 25.7 d) and JS-32 (25.6 and 24.8 d). $\mathrm{T}_{\mathrm{G} 50}$ values for stored seeds derived from population JS-04 were 8.6 and $8.3 \mathrm{~d}$, still significant faster compared with stored seeds derived from population AH-12 (10.6 and $10.5 \mathrm{~d}$ ) and JS-32 (10.1 and 10.4 d) (Table 2).

Pairwise comparisons of germination of the different seed genotypes (e.g. 1781W/W and $1781 \mathrm{M} / \mathrm{M}$ ) indicated that significant seed genotype effect on germination was observed only in fresh seeds containing 2041M/M ACCase. Germination of fresh seeds containing 2041M/M ACCase was accelerated compared with fresh seeds containing

Figure 1. Dynamics of seed germination fitted to three-parameter sigmoidal model of homozygous ACCase mutant genotype seeds and wild-type seeds in optimal experimental conditions.

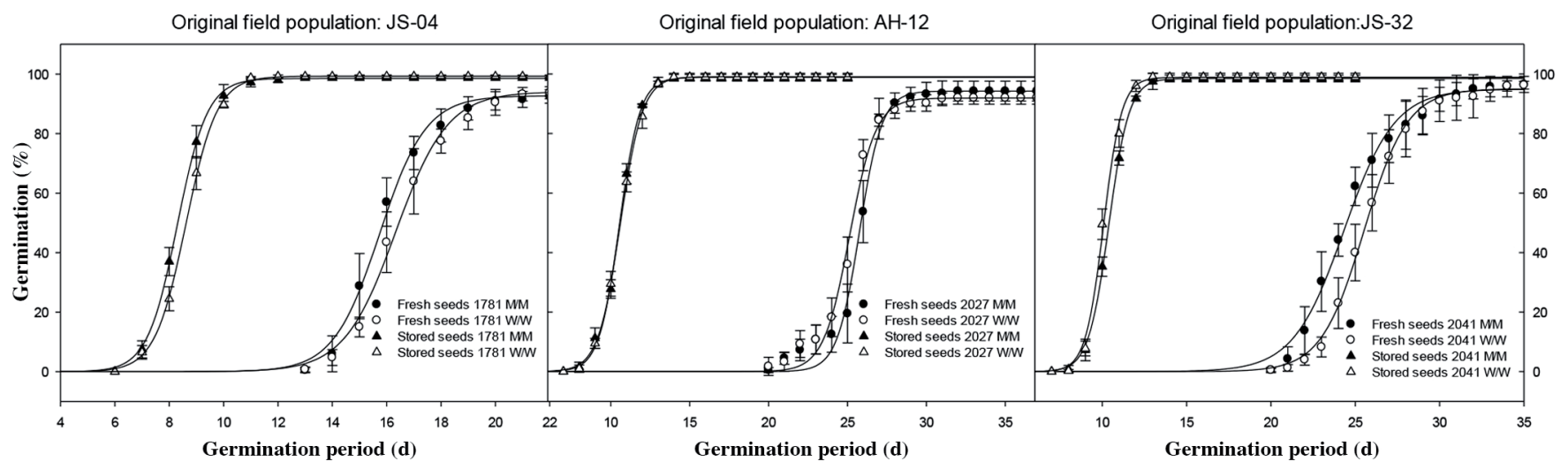

Vertical bars are SEM values.

ACCase: Acetyl-coenzyme A carboxylase; W/W: wild-type ACCase seeds; M/M: heterozygous mutant ACCase seeds. 
Table 2. Parameter estimates obtained from sigmoidal models $y(\%)=a /\left(1+\exp \left(-\left(x-t_{G 50}\right) / b\right)\right)$ that describes the dynamics of germination over time for the derived wild-type ACCase (W/W) and homozygous mutant ACCase (M/M) seeds.

\begin{tabular}{|c|c|c|c|c|c|c|c|c|}
\hline \multirow[b]{2}{*}{ Experiment } & \multirow{2}{*}{$\begin{array}{c}\text { Original } \\
\text { population }\end{array}$} & \multirow{2}{*}{$\begin{array}{c}\text { ACCase } \\
\text { allele }\end{array}$} & \multicolumn{2}{|c|}{$\mathrm{a}$} & \multicolumn{2}{|c|}{$\mathrm{t}_{\mathrm{G} 50}$} & \multicolumn{2}{|c|}{ b } \\
\hline & & & $\mathrm{W} / \mathrm{W}$ & $\mathrm{M} / \mathrm{M}$ & $\mathrm{W} / \mathrm{W}$ & $\mathrm{M} / \mathrm{M}$ & $\mathrm{W} / \mathrm{W}$ & $\mathrm{M} / \mathrm{M}$ \\
\hline \multirow[t]{3}{*}{ Fresh seeds } & JS-04 & Ile1781Leu & $94.0 \mathrm{a}$ & $93.2 \mathrm{a}$ & $16.3 \mathrm{a}$ & $15.7 \mathrm{a}$ & $0.90 \mathrm{a}$ & $0.84 \mathrm{a}$ \\
\hline & AH-12 & Trp2027Cys & $91.9 \mathrm{a}$ & $94.4 \mathrm{a}$ & $25.1 b c$ & $25.7 \mathrm{c}$ & $0.81 \mathrm{a}$ & $0.72 \mathrm{a}$ \\
\hline & JS-32 & Ile2041Asn & $95.3 \mathrm{a}$ & $95.5 \mathrm{a}$ & $25.6 \mathrm{c}$ & $24.8 \mathrm{~b}$ & $1.28 \mathrm{ab}$ & $1.56 \mathrm{~b}$ \\
\hline \multirow[t]{3}{*}{ Stored seeds } & JS-04 & Ile1781Leu & $99.3 \mathrm{a}$ & 98.6a & $8.6 \mathrm{c}$ & $8.3 \mathrm{c}$ & $0.56 \mathrm{~b}$ & $0.54 \mathrm{~b}$ \\
\hline & AH-12 & Trp2027Cys & $99.1 \mathrm{a}$ & $98.9 \mathrm{a}$ & $10.6 \mathrm{a}$ & $10.5 \mathrm{a}$ & $0.70 \mathrm{a}$ & $0.65 \mathrm{ab}$ \\
\hline & JS-32 & Ile2041Asn & $98.9 a$ & $98.5 \mathrm{a}$ & $10.1 \mathrm{~b}$ & $10.4 \mathrm{ab}$ & $0.53 b$ & $0.60 \mathrm{ab}$ \\
\hline
\end{tabular}

ACCase: Acetyl-coenzyme A carboxylase; W/W: wild-type ACCase seeds; M/M: heterozygous mutant ACCase seeds.

Different letters indicate significant differences between similar parameters with each experiment, according to Tukey's HSD test within fresh seeds or stored seeds $(\alpha=0.05)$.

$2041 \mathrm{~W} / \mathrm{W}$ ACCase, with $\mathrm{T}_{\mathrm{G} 50}$ values of 24.8 and 25.6, respectively, while in stored seeds, this trend was not observed. No matter in fresh seed test nor stored seed test, $1781 \mathrm{M} / \mathrm{M}$ and $2027 \mathrm{M} / \mathrm{M}$ ACCase showed no difference from $1781 \mathrm{~W} / \mathrm{W}$ and $2027 \mathrm{~W} / \mathrm{W}$, respectively (Figure 1, Table 2).

\section{Effect of $\mathrm{pH}$}

Results showed that seed germination of six derived subpopulation ranged from $93.2 \% \sim 99.2 \%$ over a $\mathrm{pH}$ range $4 \sim 10$. Seed germination tended to decrease slightly $(93.2 \% \sim 96.8 \%)$ at $\mathrm{pH} 4$. Over the $\mathrm{pH}$ range $6 \sim 10$, seed germination of all derived subpopulations was $>96.2 \%$. Pairwise comparisons between of homozygous mutant and wild-type ACCase seeds derived from same population showed a similar germination in all levels of acidity treatment (Figure 2).

\section{Effect of osmotic and $\mathrm{NaCl}$ salinity stress}

Seed germination of six derived subpopulation was decreased in relation to the reduction in osmotic potential caused by PEG-6000 from 0 to $-0.5 \mathrm{MPa}$ and was

Figure 2. Effect of buffered pH on germination of homozygous ACCase mutant genotypes and wild-type seeds at a constant temperature of $10^{\circ} \mathrm{C}$ with a $12-\mathrm{h}$ light cycle for $18 \mathrm{~d}$.

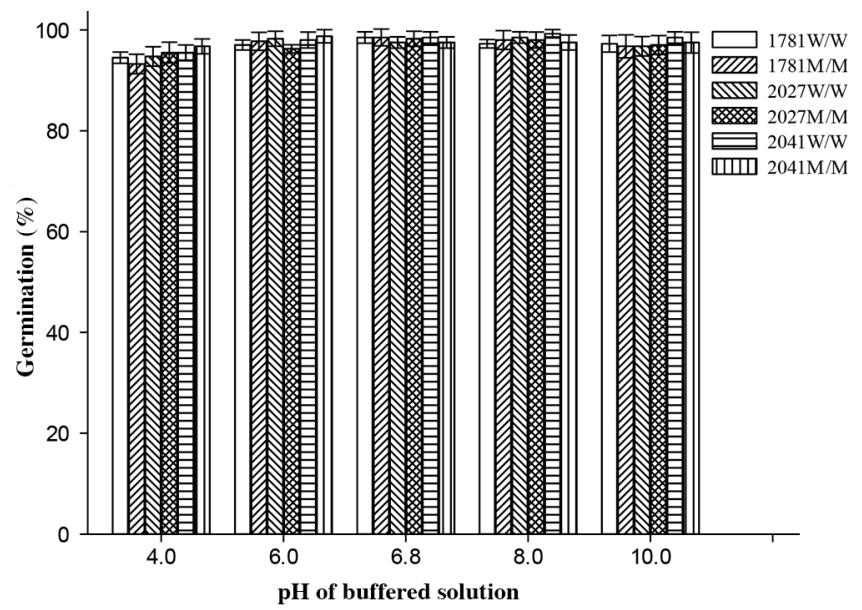

Vertical bars are SEM values.

ACCase: Acetyl-coenzyme A carboxylase; W/W: wild-type ACCase seeds; M/M: heterozygous mutant ACCase seeds. completely inhibited at $-0.6 \mathrm{MPa}$ (data not shown). Result showed a significant population effect on the germination especially at $-0.3 \mathrm{MPa}$, and seed germination of two subpopulations segregating for $2027 \mathrm{M} / \mathrm{M}$ and $2027 \mathrm{~W} / \mathrm{W}$ ACCase were obviously low compared with other four subpopulations (Figure 3). Pairwise comparisons of the germination of different seed genotypes showed that a significant effect of the seed genotype on the germination was observed for $1781 \mathrm{M} / \mathrm{M}$ ACCase over a water stress range from -0.2 to $-0.5 \mathrm{MPa}$, but not observed for $2027 \mathrm{M} / \mathrm{M}$ and 2041M/M ACCase (Figure 3). Percentage germination of seeds containing $1781 \mathrm{M} / \mathrm{M}$ ACCase was obviously higher than seeds containing 1781W/W ACCase (Figure 3).

Seed germination of six derived subpopulation was $\geq$ $96 \%$ when $\mathrm{NaCl}$ concentration was $\leq 40 \mathrm{mM}$. Germination decreased as $\mathrm{NaCl}$ concentration increased from 80 to 160 $\mathrm{mM}$, and no germination occurred at $320 \mathrm{mM} \mathrm{NaCl}$ (Figure 4). Similar to the results of the osmotic stress experiment, a significant population effect on the germination was observed at 80 and $160 \mathrm{mM} \mathrm{NaCl}$. Pairwise comparisons of homozygous mutant and wild-type ACCase seeds showed a significantly higher germination for $1781 \mathrm{M} / \mathrm{M}$ ACCase seeds

Figure 3. Effect of osmotic potential on germination of homozygous ACCase mutant genotypes and wild-type seeds at a constant temperature of $10^{\circ} \mathrm{C}$ with a 12 -h light cycle for $18 \mathrm{~d}$.

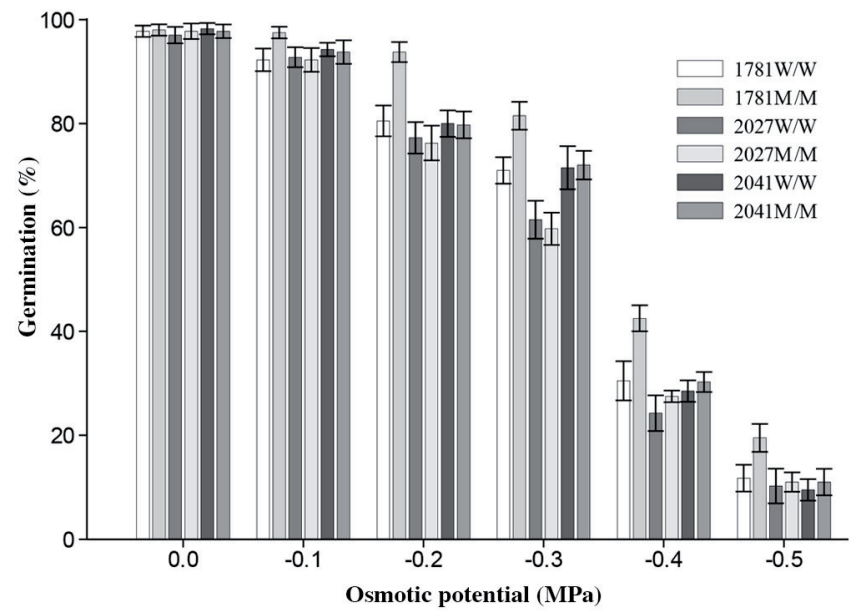

Vertical bars are SEM values.

ACCase: Acetyl-coenzyme A carboxylase; W/W: wild-type ACCase seeds; M/M: heterozygous mutant ACCase seeds. 
Figure 4. Effect of $\mathrm{NaCl}$ concentration on germination of homozygous ACCase mutant genotypes and wild-type seeds at a constant temperature of $10^{\circ} \mathrm{C}$ with a 12-h light cycle for $18 \mathrm{~d}$.

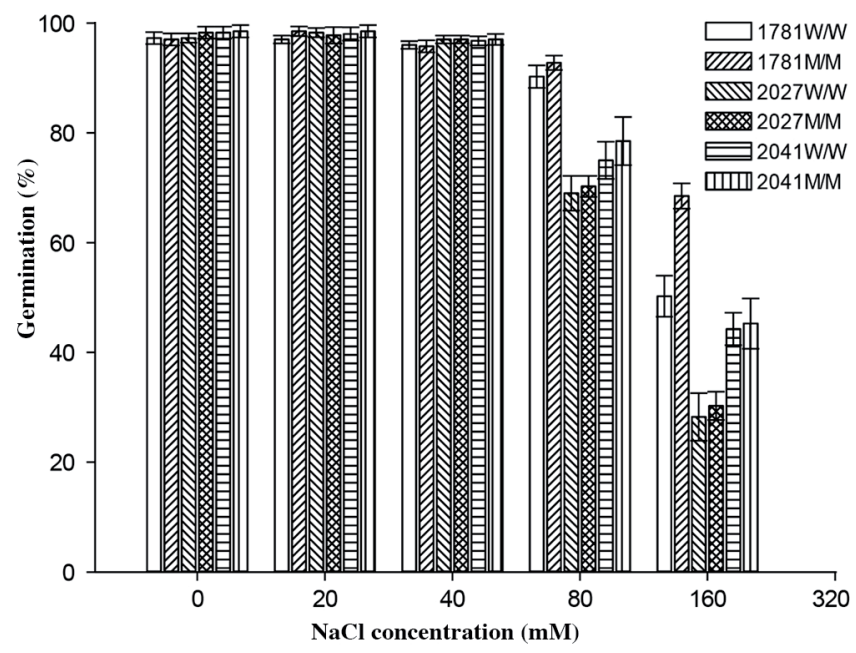

Vertical bars are SEM values.

ACCase: Acetyl-coenzyme A carboxylase; W/W: wild-type ACCase seeds; M/M: heterozygous mutant ACCase seeds.

compared with $1781 \mathrm{~W} / \mathrm{W}$ ACCase seeds at $160 \mathrm{mM} \mathrm{NaCl}$, but not for 2027M/M and 2041M/M ACCase (Figure 4).

\section{Accelerated ageing experiment}

A four-parameter logistic model $y=C+(D-C) /[1+(x /$ $\left.\left.P_{50}\right)^{b}\right]$ was fitted to the germination values $(\%)$ to calculate the incubation times causing $50 \%$ reduction in viability (persistence indices, $P_{50}$ ), an indicator of seed vigor and persistence. Where $y$ is the viability of the seeds, $x$ is the incubation time, $C$ is the lower limit, $D$ is the maximum germination (i.e. the initial viability) and $b$ indicates the slope around $\mathrm{P}_{50}$ (Seefeldt et al., 1995; Aper et al., 2014). Seed germination of six derived subpopulation was $>90 \%$ when incubation time was shorter than $4 \mathrm{~d}$. Seed viability decreased strongly after $4 \mathrm{~d}$ in the incubator, and a very low germination was found after $16 \mathrm{~d}$ incubation $(2.3 \%$ $\sim 18.7 \%$ ) (Figure 5). Regression parameters are shown in Table 3. Pairwise comparisons of regression parameters of seeds containing mutant and wild-type ACCase indicated there were no significant difference for parameter $b, D$ and $\mathrm{P}_{50}$, respectively. One interesting fact is that $2027 \mathrm{M} / \mathrm{M}$ ACCase caused higher germination $(18.7 \%)$ than $2027 \mathrm{~W} / \mathrm{W}$ ACCase (2.3\%) after $16 \mathrm{~d}$ incubation (Figure 5).

\section{DISCUSSION}

\section{Control of genetic background}

Several previous literatures had reported variation of fitness associated with resistance to ACCase inhibitors, which is not always uniform across these results (Vila-Aiub et al., 2005b; Menchari et al., 2008; Gundel et al., 2008; Owen et al., 2011). This is probably related to the genetic background such as plant species and/or populations. And in this paper, an obvious population effect on germination was observed in optimal experimental and stressful (osmotic and $\mathrm{NaCl}$ salinity) conditions. So, in order to accurately assess fitness variation associated with resistance-endowing

Table 3. Regression parameters obtained from logistic models $y=C+(D-C) /\left[1+\left(x / P_{50}\right)^{b}\right]$ in the accelerated ageing test. Seeds were incubated for $0,2,4,8$ and $16 \mathrm{~d}$ at $40{ }^{\circ} \mathrm{C}$ and $100 \% \mathrm{RH}$.

\begin{tabular}{|c|c|c|c|c|c|c|c|}
\hline \multirow{2}{*}{$\begin{array}{l}\text { Original } \\
\text { population }\end{array}$} & \multirow{2}{*}{$\begin{array}{c}\text { ACCase } \\
\text { allele }\end{array}$} & \multicolumn{2}{|c|}{$\mathrm{b}( \pm \mathrm{SE})$} & \multicolumn{2}{|c|}{$\mathrm{D}( \pm \mathrm{SE})$} & \multicolumn{2}{|c|}{$\mathrm{P}_{50}( \pm \mathrm{SE})$} \\
\hline & & $\mathrm{W} / \mathrm{W}$ & $\mathrm{M} / \mathrm{M}$ & $\mathrm{W} / \mathrm{W}$ & $\mathrm{M} / \mathrm{M}$ & $\mathrm{W} / \mathrm{W}$ & $\mathrm{M} / \mathrm{M}$ \\
\hline JS-04 & Ile1781Leu & $3.7 \pm 0.36$ & $3.9 \pm 0.99$ & $97.6 \pm 0.43$ & $98.2 \pm 0.62$ & $12.9 \pm 1.05$ & $12.7 \pm 1.14$ \\
\hline AH-12 & Trp2027Cys & $5.1 \pm 0.08$ & $4.4 \pm 0.82$ & $96.7 \pm 0.63$ & $97.8 \pm 0.37$ & $11.1 \pm 0.32$ & $11.1 \pm 0.57$ \\
\hline JS-32 & Ile2041Asn & $4.6 \pm 0.57$ & $4.6 \pm 0.78$ & $97.8 \pm 0.43$ & $98.4 \pm 0.58$ & $11.8 \pm 0.64$ & $12.1 \pm 0.32$ \\
\hline
\end{tabular}

ACCase: Acetyl-coenzyme A carboxylase; b: slope of the curve around the $\mathrm{P}_{50}$; D: upper limit (i.e. the initial viability); $\mathrm{P}_{50}$ : incubation time causing a reduction in viability of $50 \%$; w/w: wild-type ACCase seeds; M/M: heterozygous mutant ACCase seeds.

Figure 5. Regression curves for germination of homozygous ACCase mutant genotypes and wild-type seeds with increasing incubation time.

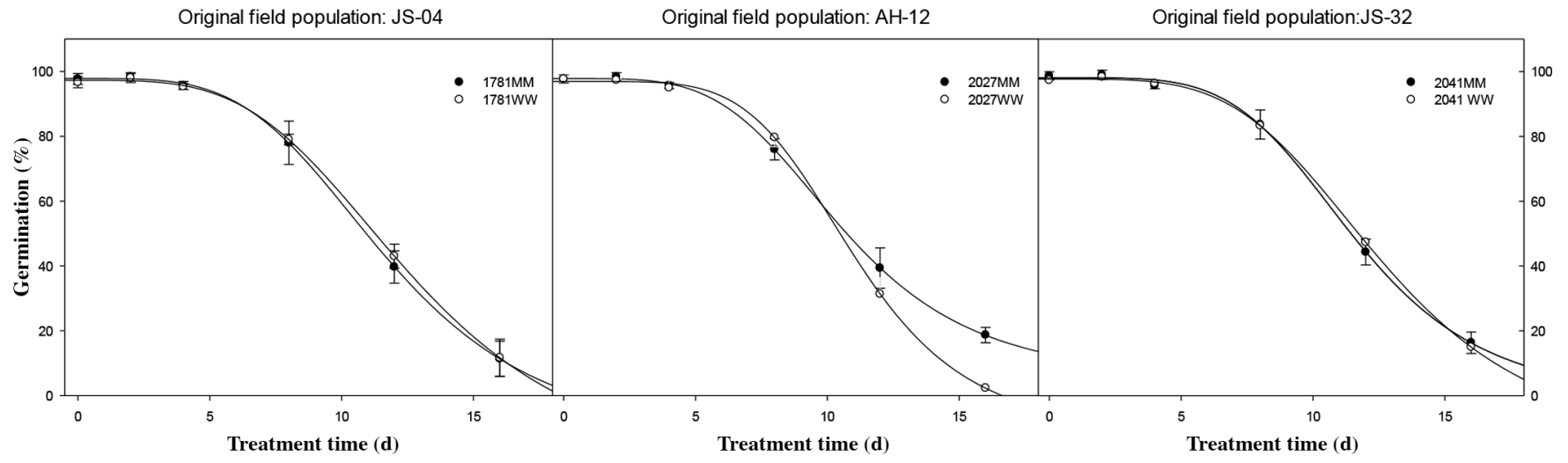

Vertical bars are SEM values.

ACCase: Acetyl-coenzyme A carboxylase; W/W: wild-type ACCase seeds; M/M: heterozygous mutant ACCase seeds. 
alleles, seeds containing homozygous mutant and wild-type ACCase should share similar genetic background, except for mutant alleles conferring herbicide resistance.

\section{Fitness cost depends on the mutant ACCase allele}

Fitness associated with Ile1781Leu ACCase had been reported in $L$. rigidum and $A$. myosuroides with controlling genetic background, and these results showed that nonsignificant fitness cost were observed in plants containing $1781 \mathrm{Leu} / \mathrm{Leu}$ ACCase (Vila-Aiub et al., 2005a; Menchari et al., 2008). One of the reasonable explanations is that this mutation did not impair ACCase activity or ACCase enzyme kinetics (Vila-Aiub et al., 2009; Yu et al., 2010). Inconsistent with results mentioned above, Ile1781Leu ACCase conferred a fitness advantage in vigor, tolerance to stress and seed output in Setaria italica produced by gene introgression (Wang et al., 2010). Alopecurus myosuroides containing 1781Leu/ Leu ACCase also showed a fitness advantage in seed germination (Délye et al., 2013). In addition, wide spread of Ile1781Leu ACCase in L. rigidum and across grass species may suggest that Ile1781Leu ACCase usually cause no fitness cost (Délye et al., 2005; Zhang and Powles, 2006; Menchari et al., 2006; Liu et al., 2007; Yu et al., 2007). In this paper, seeds containing homozygous 1781Leu/Leu ACCase showed a fitness advantage under salt and osmotic stress, but no fitness variation in optimal experimental condition. This consistent response to low osmotic potential and high salinity indicated that seeds containing 1781Leu/Leu ACCase may have a higher probability of germination under stressful conditions, and this may result in an infection from Yangtze Delta Region to north or west of China where has less annual precipitation (Rao et al., 2008). Moreover, 1781Leu/Leu ACCase caused no variation in germination over a broad range of $\mathrm{pH}$, so the soil $\mathrm{pH}$ is unlikely to be limiting factor for its further dispersal.

In Avena sterilis, Trp2027Cys ACCase tended to show nonsignificant differences between $\mathrm{S}$ and $\mathrm{R}$ populations in asymptotic maximum fresh weight and fresh weight values under non-competitive field conditions (Papapanagiotoua et al., 2015). This result is in agreement with result obtained in this paper, nonsignificant germination differences between 2027Cys/Cys and wild-type ACCase under optimal experimental conditions. It is to be noted here that seeds containing $2027 \mathrm{Cys} / \mathrm{Cys} \mathrm{ACCase}$ showed an obvious higher vigor after $16 \mathrm{~d}$ in the incubator at $40{ }^{\circ} \mathrm{C}$ and $100 \%$ $\mathrm{RH}$ in accelerated ageing experiment, but no difference in $\mathrm{P}_{50}$ compared with seeds containing wild-type ACCase. A previous study has also showed no difference in $\mathrm{P}_{50}$ between three resistant and one susceptible Chenopodium album population, but resistant and susceptible $C$. album used in this study shared several different genetic backgrounds and evolutionary histories, and this may make the conclusion less accurate (Aper et al., 2014).
Fitness associated with homozygous 2041Asn/Asn ACCase had been comprehensively illustrated at almost all key stages of the A. myosuroides life cycle such as seed germination. Seedling pre-emergence growth and plant growth or seed production in competition with wheat, and the results showed that this mutant ACCase is likely to confer no substantial fitness cost during the A. myosuroides life cycle despite a substantial overdominant reduction in fatal germination in buried seeds. In this paper, 2041Asn/ Asn ACCase caused acceleration in seed germination in fresh seeds. While in stored seeds, 2041Asn/Asn ACCase showed a similar germination dynamic compared with wildtype ACCase. This slightly phenotypic change in response to 2041Asn/Asn ACCase can be considered likely to cause no effect on seed germination in environmental conditions in the field.

Our results therefor confirm that the absence of fitness penalty associated with these three homozygous mutant ACCase alleles may be a contributing factor for resistance spread, and pleiotropic effects on seed germination associated with mutant ACCase depend on the alleles and vary with the environment. Furthermore, a significant population effects was observed in this paper, which indicated a significant difference in genetic background selected in different geographical locations. The same issue was emphasized in A. sterilis, which showed that non-resistance fitness traits may play an important role in variation of fitness between $\mathrm{R}$ and $\mathrm{S}$ A. sterilis populations (Papapanagiotoua et al., 2015). So it is necessary to control background of resistant and susceptible individuals in fitness assessing.

\section{CONCLUSIONS}

In conclusion, American slough grass seeds containing homozygous 1781Leu/Leu ACCase showed a slight fitness advantage (but significant) in germination. Homozygous 2041Asn/Asn or 2027Cys/Cys ACCase tended to cause nonsignificant effects on American slough grass seed germination.

\section{ACKNOWLEDGEMENTS}

This research was supported by the National Natural Science Foundation of China (31471787) and the Special Fund for Agroscientific Research in the Public Interest (201303031). The authors thank all the workers for assistance in conducting this research.

\section{REFERENCES}

Aper, J., Cauwer, B.D., Roo, S.D., Lourço, M., Fievez, V., Bulcke, R., et al. 2014. Seed germination and viability of herbicide resistant and susceptible Chenopodium album populations after ensiling, digestion by cattle and manure storage. Weed Research $54: 169-177$ 
Bergelson, J., and Purrington, C.B. 1996. Surveying patterns in the cost of resistance in plants. The American Naturalist 148:536-558.

Bergelson, J., Purrington, C.B., Palm, C.J., and López-Gutiérrez, J. 1996. Costs of resistance: a test using transgenic Arabidopsis thaliana. Proceedings of The Royal Society B 263:1659-1663.

Chachalis, D., and Reddy K.N. 2000. Factors affecting Campsis radicans seed germination and seedling emergence. Weed Science 48:212-216.

Délye, C., Menchari, Y., Michel, S., Cadet, É., and Corre, V.L. 2013. A new insight into arable weed adaptive evolution: mutations endowing herbicide resistance also affect germination dynamics and seedling emergence. Annals of Botany 111:681-691.

Délye, C., Zhang, X., Michel, S., Matéjicek, A., and Powles, S.B. 2005. Molecular bases for sensitivity to acetylcoenzyme A carboxylase inhibitors in black-grass. Plant Physiology 137:794-806.

Devine, M.D. 1997. Mechanisms of resistance to acetyl-coenzyme carboxylase inhibitors: a review. Pest Management Science 51:259-264.

Du, L., Liu, W., Yuan, G., Guo, W., Li, Q., and Wang, J. 2016. Cross-resistance patterns to ACCase-inhibitors in American sloughgrass (Beckmannia syzigachne Steud.) homozygous for specific ACCase mutations. Pesticide Biochemistry and Physiology 126:42-48.

Gundel, P.E., Martínez-Ghersa, M.A., and Ghersa, C.M. 2008. Dormancy, germination and ageing of Lolium multiflorum seeds following contrasting herbicide selection regimes. European Journal of Agronomy 28:606-613.

Hampton, J.G., and Tekrony, D.M. 1995. Handbook of vigour test methods. The International Seed Testing Association, Zürich, Switzerland.

Harwood, J.L. 1988. Fatty acid metabolism. Annual Review of Plant Physiology and Plant Molecular Biology 39:101-138.

Heap, I.M. 2016. International survey of herbicide resistant weeds. Available at http://weedscience.org/summary/moa. aspx?MOAID=2 (accessed 29 January 2016).

Jasieniuk, M., Brûlé-Babel, A.L., and Morrison, I.N. 1996. The evolution and genetics of herbicide resistance in weeds. Weed Science 44:176-193.

Li, L., Bi, Y., Liu, W., Yuan, G., and Wang, J. 2013a. Molecular basis for resistance to fenoxaprop-p-ethyl in American sloughgrass (Beckmannia syzigachne Steud.) Pesticide Biochemistry and Physiology 105:118-121.

Li, L., Du, L., Liu, W., Yuan, G., and Wang, J. 2014. Targetsite mechanism of ACCase-inhibitors resistance in American sloughgrass (Beckmannia syzigachne Steud.) from China. Pesticide Biochemistry and Physiology 110:57-62.

Li, M., Yu, Q., Han, H., Vila-Aiuba, M.M., and Powles, S.B. 2013b. ALS herbicide resistance mutations in Raphanus raphanistrum: evaluation of pleiotropic effects on vegetative growth and ALS activity. Pest Management Science 69:689-695.

Liu, W., Harrison, D.K., Chalupska, D., Gornicki, P., O'Donnell, C.C., Adkins, S.W., et al. 2007. Single-site mutations in the carboxyltransferase domain of plastid acetyl-CoA carboxylase confer resistance to grass-specific herbicides. Proceedings of the National Academy of Sciences of the United States of America 104:3627-3632.

Menchari, Y., Camilleri, C., Michel, S., Brunel, D., Dessaint, F., Corre, V.L., et al. 2006. Weed response to herbicides: regionalscale distribution of herbicide resistance alleles in the grass weed Alopecurus myosuroides. New Phytologist 171:861-874.
Menchari, Y., Chauvel, B., Darmency, H., and Délye, C. 2008. Fitness costs associated with three mutant acetylcoenzyme A carboxylase alleles endowing herbicide resistance in black-grass Alopecurus myosuroides. Journal of Applied Ecology 45:939-947.

Owen, M.J., Michael, P.J., Renton, M., Steadman, K.J., and Powles, S.B. 2011. Towards large-scale prediction of Lolium rigidum emergence. II. Correlation between dormancy and herbicide resistance levels suggests an impact of cropping systems. Weed Research 51:133-141.

Papapanagiotoua, A.P., Paresidoub, M.I., Kaloumenosc, N.S., and Eleftherohorinos, I.G. 2015. ACCase mutations in Avena sterilis populations and their impact on plant fitness. Pesticide Biochemistry and Physiology 123:40-48.

Pedersen, B.P., Neve, P., Andreasen, C., and Powles, S.B. 2007. Ecological fitness of a glyphosate-resistant Lolium rigidum population: Growth and seed production along a competition gradient. Basic and Applied Ecology 8:258-268.

Purrington, C.B. 2000. Costs of resistance. Current Opinion in Plant Biology 3:305-308.

Purrington, C.B., and Bergelson, J. 1997. Fitness consequences of genetically engineered herbicide and antibiotic resistance in Arabidopsis thaliana. Genetics 145:807-814.

Rao, N., Dong, L., Li, J., and Zhang, H. 2008. Influence of environmental factors on seed germination and seedling emergence of American sloughgrass (Beckmannia syzigachne). Weed Science 56:529-533.

Roux, F., Gasquez, J., and Reboud, X. 2004. The dominance of the herbicide resistance cost in several Arabidopsis thaliana mutant lines. Genetics 166:449-460.

Seefeldt, S.S., Jensen, J.E., and Fuerst, E.P. 1995. Log-logistic analysis of herbicide dose-response relationships. Weed Technology 9:218-227.

Strauss, S.Y., Rudgers, J.A., Lau, J.A., and Irwin, R.E. 2002. Direct and ecological costs of resistance to herbivory. Trends in Ecology and Evolution 17:278-285.

Tang, W., Zhou, F., Zhang, Y., and Chen, J. 2015. Resistance of American sloughgrass (Bechmannia syzigachne) populations to ACCase-inhibiting herbicides involves three different target site mutations from China. Pesticide Biochemistry and Physiology 124:93-96.

Vila-Aiub, M.M., Neve, P., and Powles, S.B. 2005a. Resistance cost of a cytochrome $\mathrm{P} 450$ herbicide metabolism mechanism but not an ACCase target site mutation in a multiple resistant Lolium rigidum population. New Phytologist 167:787-796.

Vila-Aiub, M.M., Neve, P., and Powles, S.B. 2009. Fitness costs associated with evolved herbicide resistance alleles in plants. New Phytologist 184:751-767.

Vila-Aiub, M.M., Neve, P., and Roux, F. 2011. A unified approach to the estimation and interpretation of resistance costs in plants. Heredity 107:386-394.

Vila-Aiub, M.M., Neve, P., Steadman, K.J., and Powles, S.B. 2005b. Ecological fitness of a multiple herbicide-resistant Lolium rigidum population: dynamics of seed germination and seedling emergence of resistant and susceptible phenotypes. Journal of Applied Ecology 42:288-298.

Vila-Aiub, M.M., Yu, Q., Han, H., and Powles, S.B. 2015. Effect of herbicide resistance endowing Ile-1781-Leu and Asp-2078Gly ACCase gene mutations on ACCase kinetics and growth traits in Lolium rigidum. Journal of Experimental Botany 66:4711-4718.

Wang, T., Picard, J.C., Tian, X., and Darmency, H. 2010. A herbicide-resistant ACCase 1781 Setaria mutant shows higher fitness than wild type. Heredity 105:394-400. 
Yu, Q., Collavo, A., Zheng, M., Owen, M., Sattin, M., and Powles, S.B. 2007. Diversity of acetyl-coenzyme A carboxylase mutations in resistant Lolium populations: evaluation using clethodim. Plant Physiology 145:547-558.

Yu, Q., Han, H., Vila-Aiub, M.M., and Powles, S.B. 2010. AHAS herbicide resistance endowing mutations: effect on AHAS functionality and plant growth. Journal of Experimental Botany 61:3925-3934
Zhang, X., and Powles, S.B. 2006. The molecular bases for resistance to acetyl co-enzyme A carboxylase (ACCase) inhibiting herbicides in two target-based resistant biotypes of annual ryegrass (Lolium rigidum). Planta 223:550-557. 